\title{
Pathways of Nurses in Long-term Care Hospitals: Seeking Work-life Balance
}

\author{
Samsook Kim \\ Daedong College \\ Ga Eon Lee \\ Dong-A University \\ Barbara Bowers \\ University of Wisconsin Madison School of Nursing \\ Yeonjae Jo ( $\nabla$ ws1211.snu@gmail.com ) \\ Dong-A University https://orcid.org/0000-0002-9208-0700
}

Research article

Keywords: Grounded theory, Qualitative research, Long-term care, Personnel turnover, Work-life balance

Posted Date: August 3rd, 2020

DOI: https://doi.org/10.21203/rs.3.rs-48053/v1

License: (c) (i) This work is licensed under a Creative Commons Attribution 4.0 International License. Read Full License 


\section{Abstract}

Background: This study explores the pathways of nurses in LTCHs and its underlying conditions in Korea. Nursing shortage in long-term care setting has been a worldwide concern. Although the factors of staying or leaving of nurses in long term care hospitals (LTCHs) have been reported, few studies have examined the trajectory and conditions of nurses staying in and leaving LTCHs.

Methods: A qualitative study design with a grounded theory approach was conducted. Data were collected in one to one interviews. Purposive and theoretical sampling led to the inclusion of 17 registered nurses with diverse characteristics from 14 LTCHs in a metropolitan city in South Korea. Individual, in-depth interviews were conducted. Data collection and analysis coincided. Data were analyzed using open and focused coding, constant comparison, theoretical sampling and memoing, and this enabled the construction of a substantive theory.

Results: Seeking work-life balance was the core category of nurses' pathway. Consequences of nurses' pathway were categorized into three groups: thriving, surviving, and leaving. Thriving nurses in LTCHs found meaning in their work, fostered good relationships, and saw opportunities for growth. Surviving nurses in LTCHs were enduring their jobs in LTCHs, having a work-life balance, and supportive nursing leader. Leaving group nurses wished to leave LTCHs due to lack of professional growth, unappealing work, continuing conflict, and social stigma. However, compensation, work system, and interpersonal relationships were the common moving conditions for all three groups.

Conclusions: This study provided the trajectory and conditions of nurses to enter, stay, move, or leave at LTCHs. Understanding the pathways for staying or leaving can be used as a strategy for successful retention of registered nurses in LTCHs.

\section{Background}

Care for the elderly has shifted from home to hospitals, with the number of long-term care hospitals (LTCHs) increasing by 4.0 times in the last 10 years in Korea [1]. LTCHs are experiencing a shortage of nurses, with a turnover rate of $24 \%$, far exceeding the average turnover rate of nurses (17\%) [2]. Although the number of LTCHs is rapidly increasing, the quality of hospitals and services provided by these institutions is a concern $[3,4]$.

In particular, nurses are responsible for supervising nursing assistants, coordinating care provided by other staff, and managing nursing quality [5]; thus, the low number of nurses results in difficulty ensuring quality management of nursing care. The shortage of nurses not only reduces the quality of care [6], patient safety [7] and increases the cost of management [8], it also hinders the formation and maintenance of a positive organizational culture [9]. The increased work and stress of other nurses can reduce organizational commitment, can cause other nurses to leave, and can affect hospital survival because of the declining number or closing wards [10]. Therefore, to improve the quality of services, it is essential to secure sufficient nurses [11] and to overcome challenges in the provision of competent and quality care $[12,13]$.

To improve the quality and skill of nursing services provided, it is necessary to reduce the nurses' turnover rate and increase their retention rate. To improve retention, it is important to understand the conditions, and its trajectory related to nurses' intention to leave. By gaining an understanding of the underlying conditions and their processes, it will provide those in management positions with an opportunity to address the issues and make appropriate changes, hopefully leading to higher retention [11].

There is increasing interest in the quality of care provided to older adults [14]. Previous studies of nursing staff in LTCHs have focused on exploring factors of turnover using quantitative research. Sociodemographic factors such as age, gender, marital status, and number of years in nursing have been found to be related to nurses' tendency to leave [15-18]. Factors related to reward such as payment, benefits, development opportunities for professional growth, achievement of self-goal, and satisfaction with quality care have also been revealed to be influential factors in terms of nurses' turnover [19-22]. Aspects of the work environment such as staff shortage, lack of resources, shift work, and working hours [18, 21, 23-25], as well as organizational factors including job satisfaction, organizational and occupational commitment, work demands, lack of autonomy, organizational culture, role ambiguity, and burnout were indicated as factors related to intention to leave $[15,17,20,21,24-28]$. Relational factors were also found to be highly correlated with turnover, namely role conflict and social support [20, 29-32].

Although several studies have used qualitative research methods to identify turnover and retention-related factors [33-37], studies such as that by Roberts and Bowers [38] have not identified the trajectory and its conditions of nurses' staying and leaving, as a means to provide new insights. With the growing demand for LTCH services, it is time to gather available evidence to explore the process and context by which nurses are staying in or leaving LTCHs. The purpose of this study was to understand the nurses' pathway in LTCHs over time and the related conditions.

\section{Methods}

A grounded theory design was used to explore the trajectory of LTCH nurses. Sampling, data collection, and analysis were conducted in a cyclical process. The goals of ongoing analysis guided decisions regarding theoretical sampling, interview questions, and coding, and data were progressively abstracted into a conceptual model as the study progressed [39].

\subsection{Participants and setting}

A total of 17 registered nurses working in $14 \mathrm{LTCH}$ in a metropolitan city of Korea were interviewed in this study. Eligibility criteria comprised (1) Korean registered nurses (RNs), (2) nurses participating in direct care for elderly patients, (3) over six-month' experience of working in LTCHs, and (4) full-time employees. Nursing managers and nurses who had left LTCHs were excluded. 
Participants were recruited conveniently and purposively. Researchers introduced the study purpose and data collection method at an informal LTCH managers' meeting and distributed flyers to those present to put the researchers directly in contact with nurses who wanted to participate in interviews. Participants then introduced other nurses who fit the theoretical sampling profile. There were no recruiting issues because nurses were eager to discuss their experience in new and different working environments in Korea. All participants were female with a mean age of 38.7 years (range 26-51). Eleven were staff nurses, and six were head nurses. The mean length of nursing career experience in LTCHs was 3.16 years (range 0.9-8.1 years). Eleven participants were married, and six were unmarried. Five had a diploma, eight had a bachelor's degree, and four had a master's degree.

The participants comprised three new nurses, nine reentry nurses, and five transfer nurses. The experience of nurses was measured from their initial recruitment point in LTCHs. The new nurses comprised those who had begun working at LTCHs after graduate nursing school with an average career of 0.4 years (range $0-1$ years) in acute care hospitals. Moreover, two of them were promised jobs in grand acute hospitals when any position would be available, and they were working in LTCHs in the meantime. The reentry nurses had reentered LTCHs after a parenting break with an average career of 4.8 years (range 1-8 years) in acute care hospitals. Moreover, in terms of age, six, one, and two of the reentry nurses were in their $30 \mathrm{~s}, 40 \mathrm{~s}$, and $50 \mathrm{~s}$, respectively. They were divided into a younger group, comprising those that had taken a shorter break for parenting or further study, and an older group, with those who had taken more extended parenting breaks. Transfer nurses comprised those who had transferred from acute care hospitals with average career experience of 13.3 years at acute hospitals (range 6-24.3 years). Two of five comprised nurses had retired early from acute care hospitals. The discourse extracts in the text are labeled to indicate the data source (P: Participant, interview number, N: New nurse; RO: Reentry Old nurse; RY: Reentry Young nurse; T: Transfer nurse).

The settings comprised $14 \mathrm{LTCHs}$ located in a metropolitan city in Korea. The mean number of beds in the 14 LTCHs was 171 (range 27-500), while the average age of LTCHs was 4.7 years (range 5months-9 years). Eleven of the owners of LTCHs were physicians, and three were non-medical personnel.

\subsection{Data collection and analysis}

A grounded theory approach was used in this study, which was deemed fit for understanding the process and conditions of nurses' paths in LTCHs. Once ethical approval had been obtained, data were collected by convenience sampling at the beginning of the study and by purposeful sampling as the study progressed. Data collection and analysis was an ongoing process, and constant comparative analysis and theoretical sampling were used to saturate categories and generate a conceptual model [39]. For example, the authors recruited participants to ensure variation in age and length of LTCH career experience. Moreover, the interview questions were changed as the data collection progressed, from general working experiences to more detailed information.

Data collection and analysis was accomplished three times from June 2012 to December 2016: the first round was conducted in June 2012 for two reentry participants, the second round from March to August 2013 for five reentry and five transfer participants, and the final round in December 2016 for three new nurses and two more reentries. A total of 22 interviews were conducted. Each participant was interviewed face-to-face for the first round of data collection. Two participants were interviewed a second time, and additional phone call interviews were conducted to gather supplementary information. The average interview time was approximately $50 \mathrm{~min}$ (min 35- max $90 \mathrm{~min}$ ). Having completed 22 interviews, the authors considered conceptual saturation to be sufficient as no new data were appearing to explain the conceptual model.

Participants were interviewed after completing their shifts and at a place of their convenience: either in the author's office or at a quiet cafe. The interview questions were as follows: "Tell me about your working experiences in an LTCH"; "Tell me about your motives for choosing to work in an LTCH"; "Tell me about the advantages and disadvantages of working in an LTCH"; "If you had difficulties working in an LTCH, what was helpful to overcome them?"; "What helped you to stay longer in the LTCH?". However, these questions differed for each participant and were not asked sequentially for each participant. The interview was initiated with a general question on working experience in LTCHs, and the subsequent questions were more focused on more detailed information. For example, participants initially discussed the LTCH environment with a focus on whether the system was disorganized or driven by nursing assistants. On that basis, researchers considered the next interview question regarding why they had selected their workplace. With theoretical sampling, researchers aimed to speak to nurses, who might have had specific experiences, such as new nurses entering an LTCH while waiting jobs in grand acute hospitals, which would further the conceptual model. For another example, researchers asked to speak to reentry nurses, who entered an LTCH after a long parenting break. Their experience would potentially be different than nurses with short-term parenting breaks.

The researchers attempted to listen attentively and positively in all interviews and to adopt a neutral attitude without indicating the pros and cons of the participants' statements. All interviews were audio-recorded on two recorders and transcribed verbatim to a computer document as soon as possible after the interview. During the data collection, note-taking was conducted to record details of the interview situation and participants' nonverbal expressions.

Grounded theory analysis was used, focusing on open coding and a paradigm analytic tool [39]. In the open coding, line-by-line analysis was conducted, focusing on each word, expression, and sentence to identify as many characteristics as possible. Next, constant comparative analysis was conducted to scrutinize the similarities and differences among categories. Then, using the paradigm tool, coding around categories was used to identify the relationships with each category of conditions, actions-interactions, and consequences. Finally, integration was conducted to develop a conceptual model to explain the process of nurses' pathways for LTCHs, while memoing was used for constant comparative analysis and theoretical sampling from the beginning of the study to guide the research direction, construct the next interview questions, and draw diagrams. For example, the shift in theoretical sampling related to why some participants enjoyed their jobs while others merely endured them, despite both working in the same LTCH environment. However, data analysis was processed back and forth rather than sequentially.

To ensure rigor in qualitative research, team analysis, memoing, confirmation of transcripts by participants, and member checking were conducted in relation to the findings [39]. Team analysis was conducted regularly to share ideas and to avoid authors' preconceptions and biases in the analysis. The research team was composed of four faculty members with advanced education in nursing and in qualitative health research, all of them were female registered nurse having Ph.D. degree. Moreover, the research team have conducted long-term care and qualitative researches. Consistent analysis process was extensively

Page $3 / 12$ 
performed throughout the study for data analysis and analytic process. Transcripts were returned verbatim to participants and confirmed at the beginning of the data-gathering process. Two of the nurses working in LTCH reviewed and confirmed the findings.

\subsection{Ethical considerations}

Ethical approval of the study was granted by the Institutional Review Board of Ethics at University-affiliated authors (IRB No. 12-148) before data collection, and informed written consent was obtained from each nurse who volunteered for the study. Participants were informed regarding the study purpose, data collection method, assurance of anonymity, confidentiality of the research data, right of refusal to answer questions, and the right to withdraw from the study at any time. To ensure confidentiality, interviews were conducted in private spaces.

\section{Results}

\subsection{Nurses' trajectories and conditions in long-term care hospitals}

Participants reported entering long-term care hospitals to achieve a good work-life balance, or due to the difficulty of finding a job in a large acute care hospital. They had moved from one LTCH to another twice and eventually remained in these hospitals and separated into three groups: thriving, surviving, or leaving (Fig. 1).

All participants reported that they chose to work in an LTCH to achieve a good work-life balance. Work-life balance means balancing one's personal life (such as home and hobbies) with one's occupation. Work-life balance, identified by all participants as an important factor, includes geographical proximity from home, limited number of required weekend shifts, and flexible work shifts. Geographic proximity from home saved both transportation costs and the time required for family responsibilities. Flexibility of work time was described by all nurses as the ability to negotiate work shifts in advance of employment, aligning the future work schedule with personal life and obligations outside of work, including family schedules or study time, to advance their careers.

"I wanted to care for my kids simultaneously... This hospital is very close to my house and convenient in terms of caring for my kids...and this hospital gave me the working conditions that I wanted. Working time is from nine to five. It's a good time to take care of my kids. Also, I can take every Sunday off. These working conditions were suitable for me, so I came here." P7RO

Besides work-life balance, the difficulty of finding a job in a large acute care hospital was another motivating factor for entering LTCHs. Nurses who were new to practice, nurses who had been on long career breaks, and early retired transfer nurses referenced the limited opportunities available to obtain a job in large acute care hospitals due to conditions of recruitment timing, ability, and their age, which contributed to their decision to work in an LTCH. Newly qualified nurses added that, due to their current limited opportunities, LTCH was an effective way to launch their careers by allowing them to gain experience in nursing while they were wait-listed for grand acute care hospitals.

"I failed the (school nurse) exam. I could not apply to grand acute hospitals after I had graduated one year later. There were not enough opportunities for me to take except working here. So, I came here" P14N

"It was hard for me to enter acute care hospitals because I had a very short nursing career in hospital, and had stayed at home too long after marriage. I forgot everything..." P7RO

"When I was getting old, it was so stressful studying at my work. In the previous acute hospital, I had to continually study and teach younger nurses ... That was why I came here. I wanted to have a more relaxed life." P8T

Trajectory-related conditions were categorized as work environment, organization, relationship, and intrapersonal conditions. Nurses were seeking better systems, equipment, payment, and opportunities to improve their work environment. Organizational conditions included opportunities for development and role ambiguity. Relationship-related conditions included seeking less conflict, having good relationships, and having a supportive nursing leader. Lastly, intrapersonal conditions comprised finding meaning in the profession and recognizing social stigma.

Over time, some participants stayed at the same hospital while others moved on to new LTCHs. Ten participants stayed in the same LTCH that they had first entered. These nurses were younger and had had shorter nursing careers than those who moved. Work-life balance was important to them as well as having a supportive manager who influenced their decision to work in the same hospital. Nevertheless, participants sometimes wanted to quit the hospital due to the physical burden or conflict with coworkers. At this point, the supportive role of head nurses to change them to a more relaxed schedule or to encourage staff nurses had an important influence on their decision to stay at the same LTCH.

"My head nurse always encouraged me to stay here. Whenever I was so exhausted physically, she made my schedule more suitable for me. She tried to do her best for me to stay here. Because of her, I could not leave here. I could not betray her great help. I am still working here because of her." P14N

Seven participants had experience moving within LTCHs with a maximum of two moves. These nurses were older and had had longer nursing careers than those who stayed. In this moving process, work-life balance was also revealed as the common cause. Participants moved to be closer to their homes in a bid to find a better work-life balance. Participants also moved hospitals to seek better compensation.

"This hospital gave me more holidays, more holidays... and more salary (quietly), a little bit... so I moved here." P15RY

Participants also moved hospitals to seek better organization with a better owner philosophy and better equipment. Participants presented profit-seeking owners as a salient and strong reason for moving. They discussed LTCH owners' concerns about making and saving money through examples of patients' 
documentation methods and restriction of the resources required in nursing care. This ownership directly affected nurses' negative feelings towards LTCHs, decreased their morale to work there, and eventually induced nurses to move to another organization.

"The hospital manager was not a medical-oriented person. He was just a businessman. So, we-nurses-could not talk with him about the stuff we needed. Whenever we asked for something to be bought for patient care, he always rejected it. I was so shocked at him and left just one month later." P9T

Participants also moved to new LTCHs due to better equipment, including hospital computer systems (OCSs). Nurses commented that in most LTCHs, they had to write all patients' documentation by hand because OCSs were not common. However, sometimes re-entry nurses did not want to use OCSs because they were not familiar with them. Transfer nurses from acute care hospitals, on the other hand, were good at using OCSs, and this was revealed as a moving condition for transfer nurses.

"The computer system, OCS, was the most important reason I came here. In other places, nurses have to write tons of paperwork by pencil, then write and erase with 'white' (eraser), and write it again... that job made my wrist and hands hurt so much. OCS was the biggest merit of working here." P9T

Therefore, seeking better compensation and better organization were identified as the other reasons for participants moving to new LTCHs. The final moving condition of participants was seeking less conflict with a nursing manager. They perceived nursing managers to lack the leadership skills required to manage nursing staff and their work. If nurses had several conflicts with nursing managers regarding communication and jobs, they left and moved to new settings.

"The nursing manager was extremely self-righteous. I had several conflicts with her, so I could no longer be tolerant there. So, I decided to leave there and came here." P9T

"In the previous $\mathrm{LTCH}$, the nursing manager was very obsessive about the work, too obsessive... so I could not be patient with her. She was just controlled by the hospital owner to earn money." P3T

\subsection{Thriving, surviving, and leaving}

Over time, participants separated into three groups: thriving, surviving, and leaving. Participants in the thriving and surviving groups wanted to stay longer in LTCHs in contrast with the leaving group who intended to leave. The thriving group represented nurses who enjoyed their work in LTCHs, even though they perceived the setting as lacking opportunities for professional growth and lacking recognition. They were also confronted with the unappealing everyday working conditions, had conflicts with people at work, and perceived there to be social stigma, just like the surviving and leaving groups. Age was not relevant to the thriving experience; these participants had a will that could not be swayed by external conditions. One participant said that if she had the opportunity over again to obtain a job as a new nurse, she would definitely select LTCHs as a working place without hesitation.

The conditions for thriving were finding meaning, making good relationships, and seeing opportunities to improve. Such participants perceived their job as intrinsically valuable and were satisfied with gerontological work.

"When I go to work in the morning, I have a new expectation every day. I have lots of experiences of working value here. I am very satisfied. When I go back home after finishing my duty, I am always thinking about my patients... It's my pleasure...Every female patient looks like my grandma. One elderly person who had not eaten anything for seven days said to me 'I want to eat beef soup.' So, I made some at my home and brought it in to her the very next day. She said it was so delicious and thanked me so much. Oh, I was so touched and I felt my worth as a nurse working in LTCH.” P14N

Another salient condition that contributed to nurses thriving in LTCHs was forming good relationships with elderly patients and their families, and nursing staff. Thriving nurses spoke with patients about everyday life, family issues, and even their secrets. Therefore, they knew everything about the patients: their characteristics, preferences, families, and even very personal matters. Thriving nurses described patients as their new family members but real ones made while working in LTCHs. Moreover, when patients' families perceived the good relationship they had with their parents, the family responded with a reciprocal relationship to the thriving nurses. Furthermore, when patients' families visited their parents, the thriving nurses explained their parents' conditions using common vocabulary to ensure ease of understanding. Finally, elderly patients and their families felt close to and trusted thriving nurses. These good relationships were not limited to elderly patients and their families; they also had good relationships with nursing staff, including nursing assistants and care workers. Thriving nurses respected these staff personally, listened to their demands, and helped them with their difficulties. This behavior fostered good mutual relationships with nursing staff in LTCHs.

"I talk with them about everyday life. They open their minds to me so that I know everything about their lives. I have made a new family there, and they really are my family that I have here. My patients and their families trust me. They look like a real family to me. They like me very much and rely on me." P14N

"When nursing assistants had to insert IVs in elderly patients, they felt very upset. Whenever they asked me to help, I ran over to them and helped them. And when they had communication issues with my head nurse, I played a bridging role between them and the head nurse to communicate well. So, these things made them trust me and it went well with them." P13RY

"I try to respect them (nursing assistant (NA) s, care-workers) as precious nursing staff, and to listen to what they want. When they made trouble while working here, I always tried to understand their position... When I treat them well, they will do well by me too." P3T

The final condition necessary for participants to thrive was seeing opportunities to improve the unorganized hospital system. Participants proposed and changed the system in LTCHs, focused on patient-centered care, and developed nursing staff care quality.

"At that time, if a patient couldn't afford to get fluid therapy, then he/she could not get it. I thought 'this system isn't right.' The patient should be first and the money next! I suggested this to my head nurse, and she brought the issue to the committee meeting. So, the system was changed." P14N 
"I changed the rounds system in the morning. When I went to see patients, I took all of them (the NAs) together and I explained and showed them the nursing care suitable for each patient in front of them, for them to learn. In the past, only a nurse went on patients' rounds, so they (NAs) did not know anything about the patients' conditions. If they do not know the patients, can they care for patients?" P13RY

"I had considered the bath issue for elderly patients several times and I have finally changed it. I thought that if all nursing staff participated in bathing patients, they could know the general conditions of every patient from head to foot better. When it was changed, the NAs resisted it too much. But I changed it!" P3T

Therefore, those nurses who found meaning made good relationships and saw opportunities to improve the hospital system were thriving in LTCHs.

The surviving group nurses mentioned that they were merely enduring their jobs in LTCHs without finding any meaning. These were the oldest of the three groups.

"Because this working condition fits me, fits me, I am trying to spend day after day. That's all. I do not have any value here... that story is too sad (weak voice)." P5RY

The work-life balance was the salient condition for surviving in LTCHs.

"Though the salary is small, it is close to my house and I can live in a more relaxed way than before. I think here is a good place for me to work after the age of fifty." P9T

Another condition that induced surviving nurses to stay was having a supportive nursing leader, either a head nurse or nursing manager. They expressed how, whenever they experienced difficulties with others or in completing their work, the nursing leaders managed the personnel, duty schedule, and work to support participants to stay on. These supports prevented nurses from leaving LTCHs.

"My head nurse controlled them (NAs) so that they did not exert territorial power over me. I was so much younger than them and I did not know about the LTCH system. They were trying to catch me in their nest. Without her (head nurse) help, I would had been left here." P17N

"When I considered leaving here, my head nurse considered me very much. She changed my schedule from day to evening, because evening duty is easier than day. She also encouraged me to stay here. Because of her, I endured and endured..." P6RY

"The best of this is my nursing manager. She defends me in everything... When I received phone calls at night from the hospital, it made me very stressed in my previous $\mathrm{LTCH}$. But here she takes the phone at nights. She does it for me, for me." P9T

Some participants also perceived their jobs to be dead-end because of the limited job opportunities that emerged from LTCHs due to their old age.

"I am old, so it seems hard to work in other places. I think this is suitable for me, so l'm just here..." P9T

Despite the good work-life balance, leaving group nurses wished to leave LTCHs. These were the youngest group and had an entire nursing career of over five years. The conditions contributing to intent to leave were lack of professional growth, unappealing work, and dissatisfaction with managers, continuing conflict, and social stigma. These participants felt that their nursing knowledge and skills were becoming old-fashioned, due to the lack of opportunity to learn in LTCHs. Some participants expressed their eagerness to learn about the required care of the elderly: medications, fall prevention, counseling, hospice, and end-of-life care.

"I feel that I am becoming out-of-date day by day. I can't remember the medical terms that I used so often before. I am falling behind, so I have thought about moving to an acute hospital several times. LTCH doesn't give me any chance to develop my career (such as) in hospice, end of life care..." P15RY

"I forgot everything to be learned here. Even though when I was a part-time employee in a community health center, it gave me lots of time to learn things such as PowerPoint skills or teaching methods... I learned new things there. But here I have never learned anything over the years... I have just forgotten all the things that I knew before. I am thirsty for education. I feel too distressed as a professional nurse." P4T

Some participants declared their dissatisfaction with managers, both nursing managers, and hospital owners, as the condition influencing their leaving intention. They strongly perceived that they had not received any recognition for their effort in working in LTCH due to the biased personnel assessment from the nursing manager.

"I always think about leaving here... I think I will leave here after childbirth and maternity break; I will leave here... I didn't receive any reward for my master's degree... and I had a terrible experience. I acted as a substitute for the head nurse and nursing manager while they were away but I didn't receive any rewards on my job in my performance appraisal. She doesn't utilize any evidence to appraise nursing staff, she just gives better evaluations to the people she likes. I think she is unfair and she does not show any leadership like managers in acute care hospitals." P1RY

Participants also cited as bad hospital managers, who were not concerned about staff morale, as a leaving condition.

"I do not have any satisfaction or pride as a nurse and so I want to leave LTCH. Moral support for staff is urgent. But we don't get it here. If we got it, we would serve our patients well... so the owner should be more concerned about the staff. Staff management comes first. If the hospital owner continues to act like this, then lots of staff will leave here including me..." P11RY 
Another reason for leaving LTCHs was the unappealing work conditions, including elderly deaths and lots of paperwork. Some participants discussed the difficulties of elderly deaths as an unappealing job condition since they felt frustrated by the amount of death they saw in a day.

"When patients are discharged with recovery, nurses can feel that their work has some value. But here in the LTCH, most patients are only discharged when they die. I feel so depressed when I see so many dying cases here. One or two elderly people pass away every day. Most of the elderly patients can't recover but eventually die. I can't find any value in working here as a nurse. So, I seriously think of leaving very often." P5RY

Head nurses actively reported paperwork as another unappealing job condition because head nurses played a role in regular governmental evaluation.

"That regular accreditation evaluation is obligatory for LTC hospitals. But it gives too much paperwork to do. That pile of papers. When it arrives, the patients are almost left alone. We don't have time to take care of them. Nurses are always saying, 'I will leave before this coming accreditation."' P15RY

Continuing conflict with nursing assistants was another reason cited by participants for wanting to leave LTCHs. They discussed how LTCHs are a nursing assistant driven setting because NAs outnumber RNs as nursing staff and play a similar role to RNs. Therefore, nurses perceived NAs as having power in LTCHs and reported that if nurses could not endure this environment, then they could not work in LTCHs. This continuing conflict was prominent in transfer nurses, who mentioned that the structure was very different from acute care hospitals.

"The hardest job in here is to manage them (NA) as a head nurse. They have power here to control things because there are more of them than (registered) nurses and they are also older than us (RNs). I have heard that the previous head nurses left here because of them. It's a hard job for me..." P3T

"NAs pushed RNs, including the head nurse out of the ring. They are too harsh to control. They have a territorial power here. If a nurse can't endure this situation, the nurse will leave the LTCH. It's very important to manage them here, LTCH." P4T

"The hard job is to manage them here. I don't know how to treat them, because their job is very similar to mine, RN. They are too much older than me, like my mom. It is so hard..." P12T

The final condition for leaving was the social stigma. Participants perceived this from elderly patients, their families, acute care nurses, and nursing teachers. They also perceived their ignorance as unknowledgeable nurses compared to acute care nurses. They described how elderly patients and their families tested their medical knowledge. They also felt ignorance from nurses working in acute care hospitals when a patient who had transferred there asked something about the elderly patients. Even nursing teachers were curious about why participants would choose to work in LTCHs. This social stigma prompted participants to leave LTCHs.

"(My teacher asked me) Why are you working there as a young (nurse)? That's a place for old nurses who can't get a job anywhere else. My friends don't know that I am working here. I have not told them. I am not sure, but I feel a little ashamed. I think I am working here, in an LTCH, because of my lack of competence to work at acute hospitals, which seem like very active and vivid places. But here, it seems like a very passive and dim place to stay with old patients, nurses who are too old, and old physicians. Frankly, I do not want to stay here any longer." P16N

Therefore, nurses entering LTCHs for a work-life balance, either staying in the same place or moving to a new place, were finally divided into thriving, surviving, and leaving groups over time. The most noticeable condition in this passage was work-life balance, although thriving participants had also found new meaning at work. Therefore, seeking a work-life balance and meaning through caring were the essential components of the pathway for nurses working in LTCHs.

\section{Discussion}

This grounded study has attempted to deeply and integrally explore the process of nurses' movements through long-term care hospitals and its related conditions. The key condition in the process of moving to another long-term care hospital was work-life balance. The major reason for joining and remaining in an LTCH was also work-life balance. Nurses prefer to have flexible working hours, such as working a fixed shift or avoiding weekend work. Another major preference is a short commute time from home to hospital. By reducing the time required for commuting, more time can be reserved for family. If a nurse finds a more flexible schedule or better working hours in another hospital than in their current hospital, or a shorter commute time than their current employment, they are more likely to leave the hospital.

This finding provides support for previous studies, which found that work-family conflict was positively related to turnover intention and negatively related to job satisfaction [40,41]. McGilton et al. [42] asserted that nurses stay because of proximity, shift predictability, and personal life roles, such as taking care of family. Family-friendly policies and environments, which have favorable effects on reducing work-family conflict, increasing positive attitudes toward the job, and attracting and retaining employees, are suggested [43]. The result of this turnover and retention process led us to identify three groups: the thriving group, surviving group, and leaving group. These three groups had common moving conditions: compensation, work system, and interpersonal relationships.

Better work systems and sufficient resources with a computerized record management system were perceived as contributing to job satisfaction and retention. Several nurses stated that their employers were seeking profit and limited necessary medical resources to reduce costs. This was not only immoral but also seriously deteriorated the quality of care. Consistent with their responses, Castle [44] noted that for-profit ownership is associated with higher nurse turnover. Computerized data management systems were also identified as related to the turnover phenomenon. Many documents must be prepared and managed due to regular evaluation of certified hospitals, and without a computerized system, medical records must be written by hand, which unnecessarily increases the time required for administrative work. Other studies also reported the increasing demand for paperwork, which deprives direct patient care time from nurses [45-47]. 
Compensations affecting turnover include good pay. Nurses expect to receive higher remuneration than nurse assistants since they have a higher level of education and more qualifications than them. However, since the distinction in role between nurse and nurse assistant is ambiguous, leading to role conflicts, nurses are not always financially rewarded. As mentioned by Park and Yeom [48], the nursing job delegation of unclear regulations leading to role conflict, frustration, and dissatisfaction can impact their turnover intention. The positive relationship of inadequate monetary benefits with turnover intention has been commonly reported in previous studies $[45,47]$.

As suggested by Sellgren et al. [34], salary has become increasingly important; the issue of financial incentives must be addressed. The issues of inadequate financial and professional incentives referring to the non-financial incentives, which contribute to a sense of professionalism among nurses, have combined to form a vicious cycle. Nurses who are unsatisfied with their salary seek other rewards, such as recognition from oneself and others. Those who find work conditions unbearable because of role conflict are gradually inclined to voluntary turnover. Apart from the monetary issue, evidence from previous studies has upheld the unprotected doctor's job performance of nurse, and unsystematic nursing assistant management were noted [48]. To solve this problem, researchers asserted the importance of understanding nursing work and the context of practice of nurses [49].

Interpersonal relationships at work have also been found to enhance nurses' coping abilities [30]. Three domains were found that were related to nurses' relationships: patients and their families, colleagues, and managers, or supervisors. In cases where nurses have communication problems or conflicts at work, they are more likely to leave the hospital. However, nurses who recognized themselves as having social support from managers and supervisors reported a high level of intent to stay in the hospital. Findings from previous research advocate the importance of social support from colleagues, which influences the intention of nurses to leave $[50,45]$.

Moreover, previous studies have reported that good communication with supervisors is positively associated with intention to remain at a job [20, 31, 51, 52]. Furthermore, nurses who have a good rapport with patients and their families and those who have developed reliability have a sense of job satisfaction and thus thrive at their jobs. This was consistent with Abrahamson et al. [53] and Choi et al. [45], which revealed strong professional values and satisfaction gained from the recognition of care recipients. Hwang and Chang [32] reported that "workgroup friendliness and warmth" was negatively associated with intention to leave because it contributed to conflict reduction. This observation is consistent with the reports of informants on mutual respect, meeting requirements of counterparts, and helping each other, which can reduce conflict and thus lead to prosperity. The supportive interpersonal relationship among colleagues has symbolically represents intimacy, trust, and connectedness in supporting their work [45].

The reorganization of the workload, reallocation of resources, and provision of supportive leadership by nursing management are crucial factors in increasing nurses' intention to stay. By offering support and maintaining good communications, leaders can help counteract complaints and exhaustion of nurses caused by high-demand work environment [51, 52]. The establishment of a social support system and management skill training are suggested.

The salient condition in retention of thriving nurses was finding meaning at work; recognition of work and profession. Regardless of the influence of demanding and unfavorable work environment as well as relationship problems, thriving nurses in this study demonstrated professional values that helped them sustain at the same hospital. They recognized their work as meaningful. They had a professionalism, which was strengthened by patients in LTCHs. Consistent with these results, Choi et al. [45] noted that nurses gained professional value from care recipients.

Apart from gaining satisfaction from recognition, these nurses acquired a sense of accomplishment from advancing their skills in comprehensive care and care coordination at work. Nurses achieved professional development through the holistic delivery of care for older adult patients. Furthermore, in addition to providing direct care, nurses acquired a sense of accomplishment by focusing on indirect nursing tasks, such as overseeing medication management, close surveillance of direct care activities provided by other staff members, and education of nursing assistants and care-workers. Moreover, apart from gaining a sense of professionalism and accomplishment, advanced knowledge gained through the patient care process is a crucial factor for retention [45].

Professional incentives, such as the opportunities provided to fulfill their potential, were commonly identified in previous studies [54, 55]. McNeese-Smith [47] noted that the lack of learning related to the turnover of nurses, and similarly, informants of the leaving group subsequently left because of fewer development opportunities. They wanted to start their careers in LTCHs with an expectation of professional growth; however, these needs were unmet over time. Moreover, several nurses complained regarding the social stigma attached to nurses in LTCHs, with an informant describing this job as "dead end." Thus, changing the perspective of nurses on LTCHs as a specialized work environment, where they can train in hospice, end-of-life care, counseling, elderly specific medication, and fall prevention. Since career opportunities and practice environments are crucial in improving nurse satisfaction [18], career advancement opportunities should be provided for nurses specializing in gerontology [25].

\section{Conclusions}

This study has revealed the nurses' pathway in LTCHs and the conditions that influence either staying or leaving. Work-life balance was the most salient condition impacting these decisions in LTCHs. The consequences of nurses' pathway were categorized into three groups; thriving, surviving, and leaving. Thriving nurses in LTCHs and find meaning in their work, foster good relationships, and see opportunities for growth. Surviving nurses in LTCHs were enduring their jobs in LTCHs, having a work-life balance, and supportive nursing leader. Leaving nurses wished to leave LTCHs due to lack of professional growth, unappealing work, continuing conflict, and social stigma. The common moving conditions for all three groups were compensation, work system, and interpersonal relationships. Understanding the pathways to thriving, surviving, or leaving, serves as a guide to successful retention for registered nurses in LTCHs. This study provides an overview of the processes and factors in nursing that are related to nurses' intention to leave or stay in employment in LTCHs. However, the findings are restricted to interviews between 2012 and 2016 and may not include recent changes of LTCHs in Korea. Another limitation of this research is that informants who had left LTCHs were not included. It is suggested that other related factors, conditions, and working processes be investigated in further study. 


\section{Abbreviations}

\section{$\mathrm{LTCH}$}

long-term care hospital

RN

registered nurse

$P$

participant

$\mathrm{N}$

new nurse

RO

reentry old nurse

RY

reentry young nurse

$\mathrm{T}$

Transfer nurse

ocs

hospital computer system

NA

nursing assistant

\section{Declarations}

\section{Ethics approval and consent to participate}

Ethical approval was obtained from the Institutional Review Board of Dong-A University (IRB No. 12-148). All informants gave written consent to participate.

\section{Consent for publication}

Not applicable.

\section{Availability of data and material}

The datasets generated during the current study are not publicly available due to the sensitive and personal nature of the information contained in the data. Data may be available from the current authors, with restrictions and following ethical approval.

\section{Competing interests}

The authors declare that there are no competing interests.

\section{Funding}

Not applicable.

\section{Authors' contributions}

SK: Conceptualization, Methodology, Resources, Data curation, Formal analysis, Investigation, Writing - Original Draft preparation.

GEL: Conceptualization, Methodology, Resources, Data curation, Validation, Formal analysis, Investigation, Writing - Original Draft preparation, Visualization, Project administration.

BB: Methodology, Validation, Formal analysis.

YJ: Validation, Formal analysis, Writing - Review \& Editing, Visualization.

\section{Acknowledgments}

The authors would like to thank all the informants for their willingness and openness to share their time, stories, and experience.

\section{References}

1. Korean Statistical Office: Korean Statistical Information Service. http://kosis.kr/statHtml/statHtml.do? orgld=354\&tblld=DT_HIRA43\&vw_cd=MT_ETITLE\&list_id=D1_2_2_5\&scrld=\&seqNo=\&language=en\&obj_var_id=\&itm_id=\&conn_path=A6\&path=\%252Feng (2019). Accessed 20 Dec 2019.

2. Korean Hospital Nurses Association. Survey on the status of nursing staff placement. 2016 / Korean Hospital Nurses Association. A survey on hospital nursing staffing 2016. Business report for Hospital Nurses Association. Seoul: Korean Hospital Nurses Association; 2016. 
3. Allen D. What do you do at work? Profession building and doing nursing. Int Nurs Rev. 2007;54(1):41-48.

4. Bogossian F, Winters-Chang P, Tuckett A. "The Pure Hard Slog That Nursing Is...": A Qualitative Analysis of Nursing Work. J Nurs Scholarsh. 2014;46(5):377-388.

5. Montayre J, Montayre J. Nursing work in long-term care: an integrative review. J Gerontol Nurs. 2017;43(11):41-49.

6. Hassmiller SB, Cozine M. Addressing the nurse shortage to improve the quality of patient care. Health Aff. 2006;25(1):268-274.

7. Buerhaus PI, Donelan K, Ulrich BT, Norman L, Dittus R. Is the shortage of hospital registered nurses getting better or worse? Findings from two recent national surveys of RNs. Nurs Econ. 2005;23(2):61-71.

8. Jones CB. Revisiting nurse turnover costs: adjusting for inflation. J Nurs Adm. 2008;38(1):11-18.

9. McNeese-Smith DK, Nazarey M. A nursing shortage: Building organizational commitment among nurses/practitioner application. J Healthc Manag. 2001;46(3):173.

10. Lee Y, Kim J, Lee Y, Kang D, Park J. A Survey on the Status of Nursing Manpower Supply and Nursing Management Fee Differential System. Seoul: Korea Small \& Medium Hospital Council, Korea Health Industry Development Institute; 2008.

11. Chan ZC, Tam WS, Lung MK, Wong WY, Chau CW. A systematic literature review of nurse shortage and the intention to leave. J Nurs Manag. 2013;21(4):605-613.

12. Jones J, Cheek J, Ballantyne A. Providing residential care to older Australians: Issues for registered nurses. Contemp Nurse. 2002;12(3):225-234.

13. Schirm V, Albanese T, Garland TN, Gipson G, Blackmon DJ. Caregiving in nursing homes: Views of licensed nurses and nursing assistants. Clin Nurs Res. 2000;9(3):280-297.

14. Tuckett A, Hughes K, Gilmour J, Hegney D, Huntington A, Turner C. Caring in residential aged- Qualitative findings from an e-cohort sub-study. J Clin Nurs. 2009;18(18):2604-2612.

15. Hart SE. Hospital ethical climates and registered nurses' turnover intentions. J Nurs Scholarsh. 2005;37(2):173-177.

16. El-Jardali F, Dimassi H, Dumit N, Jamal D, Mouro G. A national cross-sectional study on nurses' intent to leave and job satisfaction in Lebanon: implications for policy and practice. BMC Nurs. 2009;8(1):3.

17. Liou SR, Cheng CY. Organisational climate, organisational commitment and intention to leave amongst hospital nurses in Taiwan. J Clin Nurs. 2010;19(11-12):1635-1644.

18. Ma JC, Lee PH, Yang YC, Chang WY. Predicting factors related to nurses' intention to leave, job satisfaction, and perception of quality of care in acute care hospitals. Nurs Econ. 2009;27(3):178.

19. Zeytinoglu IU, Denton M, Davies S, Baumann A, Blythe J, Boos, L. Deteriorated external work environment, heavy workload and nurses' job satisfaction and turnover intention. Can Public Policy. 2007;33 Suppl 1:S31-S47.

20. Estryn-Behar M, Van Der Heijden BI, Fry C, Hasselhorn HM. Longitudinal analysis of personal and work-related factors associated with turnover among nurses. Nurs Res. 2010;59(3):166-177.

21. Flinkman M, Laine M, Leino-Kilpi H, Hasselhorn HM, Salanterä S. Explaining young registered Finnish nurses' intention to leave the profession: a questionnaire survey. Int J Nurs Stud. 2008;45(5):727-739.

22. Triandis HC. Individualism \& collectivism. New directions in social psychology. Taylor \& Francis; 1995.

23. Reeves R, West E, Barron D. The impact of barriers to providing high-quality care on nurses' intentions to leave London hospitals. J Health Serv Res Policy. 2005;10(1):5-9.

24. Fochsen G, Sjögren K, Josephson M, Lagerström M. Factors contributing to the decision to leave nursing care: a study among Swedish nursing personnel. J Nurs Manag. 2005;13(4):338-344.

25. Mrayyan MT. Nurse job satisfaction and retention: comparing public to private hospitals in Jordan. J Nurs Manag. 2005;13(1):40-50.

26. Chang CS, Du PL, Huang IC. Nurses' perceptions of severe acute respiratory syndrome: relationship between commitment and intention to leave nursing. $J$ Adv Nurs. 2006;54(2):171-179.

27. Liou SR, Grobe SJ. Perception of practice environment, organizational commitment, and intention to leave among Asian nurses working in US hospitals. J Nurses Prof Dev. 2008;24(6):276-282.

28. Jacobs E, Roodt G. Organisational culture of hospitals to predict turnover intentions of professional nurses. Health SA. 2008;13(1):63-78.

29. O'BRIEN-PALLAS L, Murphy GT, Shamian J, Li X, Hayes LJ. Impact and determinants of nurse turnover: a pan-Canadian study. J Nurs Manag. 2010;18(8):1073-1086.

30. AbuAIRub RF, Omari FH, Al-Zaru IM. Support, satisfaction and retention among Jordanian nurses in private and public hospitals. Int Nurs Rev. 2009;56(3):326-332.

31. Chen HC, Chu Cl, Wang YH, Lin LC. Turnover factors revisited: a longitudinal study of Taiwan-based staff nurses. Int J Nurs Stud. 2008;45(2):277-285.

32. Hwang Jl, Chang H. Work climate perception and turnover intention among Korean hospital staff. Int Nurs Rev. 2009;56(1):73-80.

33. Newman K, Maylor U, Chansarkar B. The nurse satisfaction, service quality and nurse retention chain. J Manag Med. 2002;16(4):271-291.

34. Sellgren SF, Kajermo KN, Ekvall G, Tomson G. Nursing staff turnover at a Swedish university hospital: an exploratory study. J Clin Nurs. 2009;18(22):31813189.

35. Flinkman M, Isopahkala-Bouret U, Salanterä S. Young registered nurses' intention to leave the profession and professional turnover in early career: a qualitative case study. ISRN nurs. 2013; doi:10.1155/2013/916061. 
36. Hayward D, Bungay V, Wolff AC, MacDonald V. A qualitative study of experienced nurses' voluntary turnover: learning from their perspectives. J Clin Nurs. 2016;25(9-10):1336-1345.

37. Flinkman M, Salanterä S. Early career experiences and perceptions-a qualitative exploration of the turnover of young registered nurses and intention to leave the nursing profession in Finland. J Nurs Manag. 2015;23(8):1050-1057.

38. Roberts T, Bowers B. How nursing home residents develop relationships with peers and staff: A grounded theory study. Int J Nurs Stud. $2015 ; 52(1): 57-67$.

39. Corbin J, Strauss A. Basics of qualitative research: Techniques and procedures for developing grounded theory. $4^{\text {th }}$ Sage publications; 2014.

40. Brewer CS, Kovner CT, Greene W, Cheng Y. Predictors of RNs' intent to work and work decisions 1 year later in a US national sample. Int J Nurs Stud. 2009;46(7):940-956.

41. Chen IH, Brown R, Bowers BJ, Chang WY. Work-to-family conflict as a mediator of the relationship between job satisfaction and turnover intention. J Adv Nurs. 2015;71(10):2350-2363.

42. McGilton KS, Boscart VM, Brown M, Bowers B. Making tradeoffs between the reasons to leave and reasons to stay employed in long-term care homes: Perspectives of licensed nursing staff. Int J Nurs Stud. 2014;51(6):917-926.

43. Skinner N, Chapman J. Work-life balance and family friendly policies. Evidence Base. 2013;4:1-25.

44. Castle NG. Measuring staff turnover in nursing homes. Gerontologist. 2006;46(2):210-219.

45. Choi J, Flynn L, Aiken LH. Nursing practice environment and registered nurses' job satisfaction in nursing homes. Gerontologist. 2012;52(4):484-492.

46. Hallin K, Danielson E. Registered nurses' experiences of daily work, a balance between strain and stimulation: A qualitative study. Int J Nurs Stud. 2007;44(7):1221-1230.

47. McNeese-Smith DK. A content analysis of staff nurse descriptions of job satisfaction and dissatisfaction. J Adv Nurs. 1999;29(6):1332-1341.

48. Park S, Yeom EY. Experience of the role conflict of nurses in long-term care hospitals. The Journal of the Korea Contents Association. 2016;16(7): 368381.

49. Spitzer R. Keys to avoiding a high rate of CNO turnover. Nurse Lead. 2006;4(5):4-5.

50. Van der Heijden BIJM, Kümmerling A, Van Dam K, Van der Schoot E, Estryn-Béhar M, Hasselhorn HM. The impact of social support upon intention to leave among female nurses in Europe: Secondary analysis of data from the NEXT survey. Int J Nurs Stud. 2010;47(4):434-445.

51. Bakker AB, Killmer CH, Siegrist J, Schaufeli WB. Effort-reward imbalance and burnout among nurses. J Adv Nurs. 2000;31(4):884-891.

52. Schmieder RA, Smith CS. Moderating effects of social support in shiftworking and non-shiftworking nurses. Work Stress. 1996;10(2):128-140.

53. Abrahamson K, Jill SJ, Pillemer K. Conflict between nursing home staff and residents' families: does it increase burnout?. J Aging Health. 2009;21(6):895912.

54. Lu KY, Lin PL, Wu CM, Hsieh YL, Chang YY. The relationships among turnover intentions, professional commitment, and job satisfaction of hospital nurses. J Prof Nurs. 2002;18(4):214-219.

55. Teng Cl, Shyu YIL, Chang HY. Moderating effects of professional commitment on hospital nurses in Taiwan. J Prof Nurs. 2007;23(1):47-54.

\section{Figures}

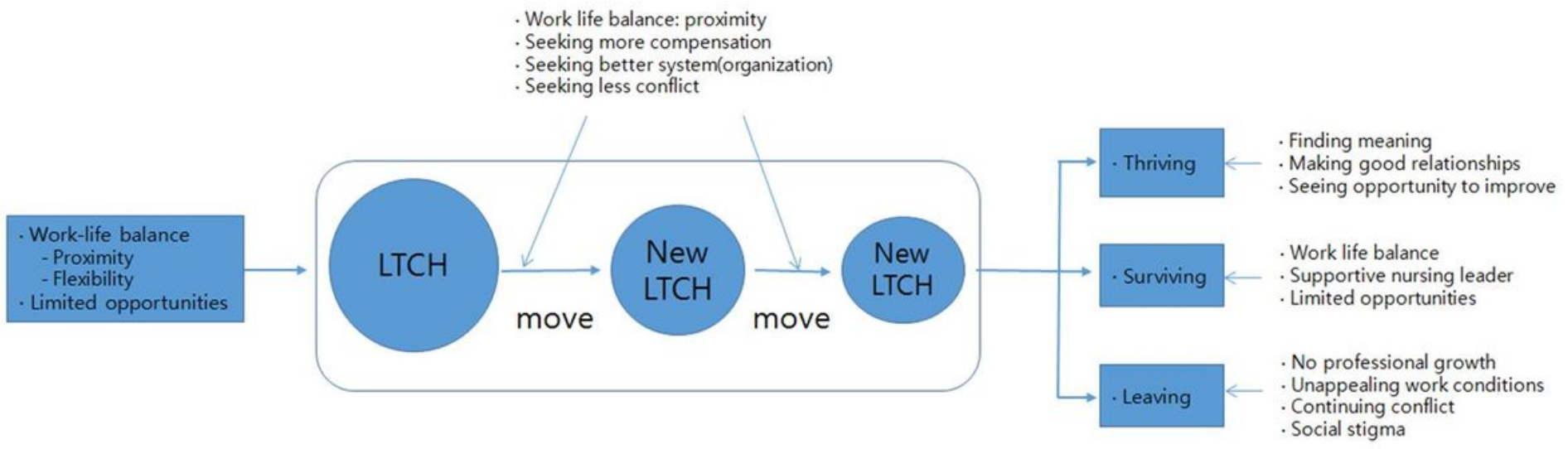

\section{Figure 1}

Pathways of nurses in long-term care hospitals: seeking work-life balance.

\section{Supplementary Files}

This is a list of supplementary files associated with this preprint. Click to download. 
- COREQ.docX

Page 12/12 